\title{
VARIA
}

\section{DOS GUIRNALDAS FIRMADAS POR BARTOLOMÉ PÉREZ}

Con evidente razón se viene considerando a Bartolomé Pérez como al segundo pintor de flores en España, después de su suegro Juan de Arellano. Con él se formó y de él hubo de adquirir sus mejores virtudes pictóricas lo que en ocasiones ha producido, cuando sus pinturas no están firmadas, que se confundan ambos artistas. En torno a 1655 Pérez debió de independizarse del taller de su suegro y desde esta fecha se comportó con personalidad artística propia. Esta situación de independencia con respecto a Arellano propició que Pérez pudiera desplegar un sentido pictórico individualizado al cual pudo aportar entre otros aspectos un excelente dibujo que reflejó no sólo en la descripción de las flores, sino en cuantas ocasiones pudo introducir en sus obras aspectos relacionados con la figura humana.

En una colección particular de Madrid se conservan actualmente dos Guirnaldas de flores firmadas y fechadas en 1680 por este artista; ambas proceden de una colección privada de Sevilla, donde han permanecido los últimos treinta años; a su vez proceden de una colección de Málaga, donde consta su existencia al manos desde principios del presente siglo (véanse Figs. 1 y 2).

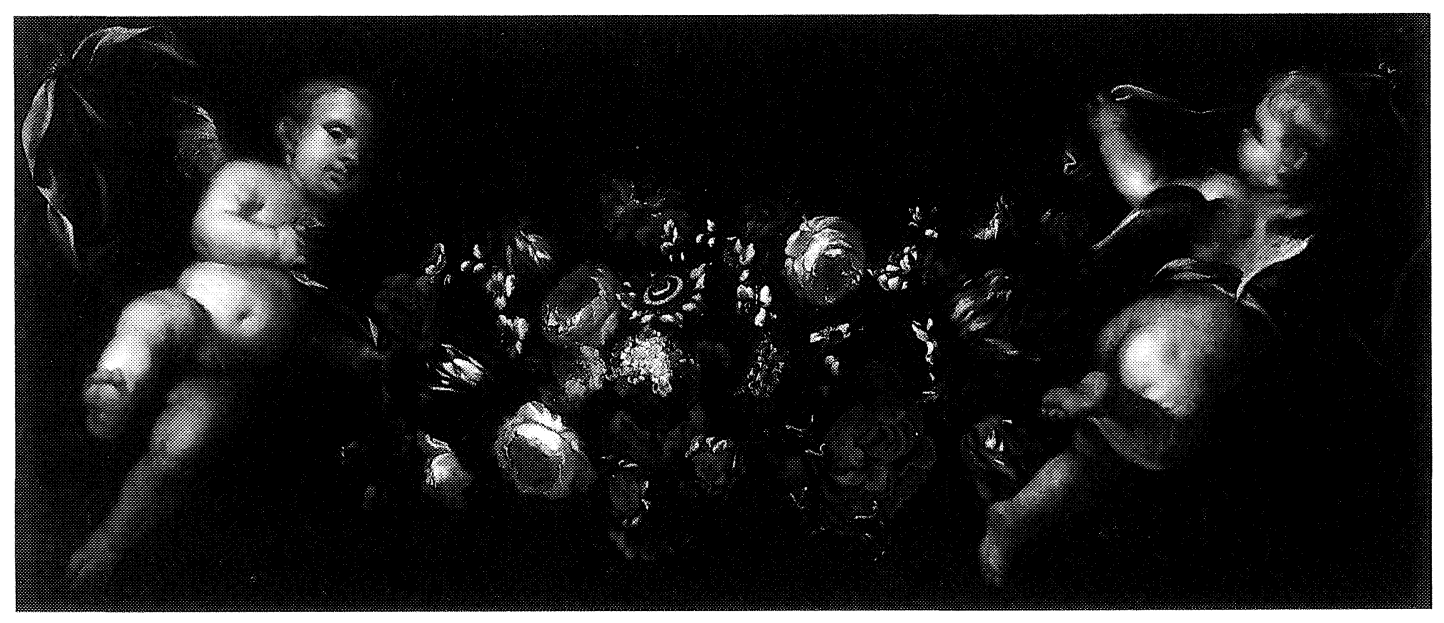

Fig. 1. Bartolomé Pérez. Guirnaldas de Flores. Madrdid. Colección particular. 


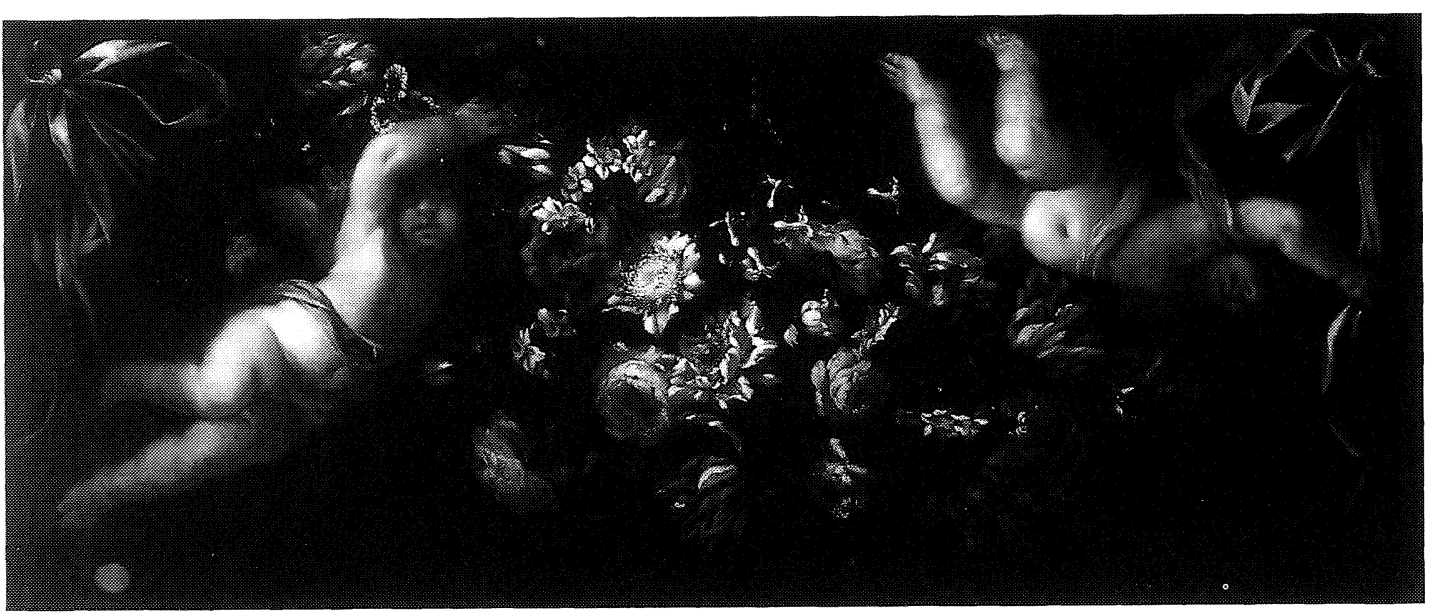

Fig. 2. Bartolomé Pérez. Guirnaldas de Flores. Madrdid. Colección particular.

Las dos guirnaldas están sostenidas a cada una de ellas por amorcillos volanderos cuyo dibujo viene a confirmar el buen crédito que Pérez ha tenido siempre como pintor de flores y de figuras ${ }^{1}$. Constituyen estas guirnaldas una interesante aportación al catálogo de este artista, cuya nómina de obras firmadas es escasa. Los amorcillos y las flores que conforman la figuración de estas pinturas destacan sobre un fondo de penumbra gris verdoso; las flores cuelgan de unas argollas que figuran en los laterales donde aparecen sujetándolas ampilosos lazos azules y los amorcillos que la sostienen están resueltos con atrevidos escorzos que traducen movidas y agitadas actitudes resueltas con un dibujo que acedita a Bartolomé Pérez como un buen conocedor de la anatomía humana y de su correspondiente disposición en el espacio. Por otra parte se advierte en las pinturas el empleo de una pincelada suelta y provista de abundante pasta cromática, detalle técnico que las otorga una grata percepción visual.

El formato apaisado de estas dos obras sugiere que fueron realizadas como sobrepuertas y formando pareja, ya que entre la disposición de las flores y la actitud de los amorcillos se observa una clara correspondencia de efectos compositivos al tiempo que juegos de colores alternantes y armoniosos en sus matices cromáticos.

Corresponden estas pinturas al período de plenitud de Bartolomé Párez, puesto que están realizadas en un momento culminante de su existencia; en efecto, en 1680 contaba con 46 años de edad y aún le quedaban 18 de vida.

ENRIQUE VALDIVIESEO Universidad de Sevilla

\footnotetext{
${ }^{1}$ Miden $61 \times 141 \mathrm{~cm}$. Ambas están firmadas $B^{m e} P z f a c$ Ao 1680. Sobre este artista las referencias bibliográficas fundamentales son A: Palomino, Museo pictórico... 1724, ed. 1974, p. 1058; A. Ceán Bermúdez. Diccionario... 1800, IV, p. 73; J. Cavestany, Floreros y bodegones en la pintura española, 1936-1940, p. 85; M. Agulló, Más noticias sobre pintores madrileños de los siglos XVI al XVII. Madrid, 1981; E. Valdivieso, Obras maestras de colecciones particulares. Sevilla, 1982, donde se dan a conocer, números 14 y 15, dos guirnaldas haciendo pareja, una de ellas firmada $B^{m e}$ Pz pr regis; A. Pérez Sánchez. Catálogo de la Exposición «Pintura española de bodegones y floreros de 1600 a Goya», p. 99; Id. La nature morte spagnole du XVIII siècle á Goya. París, 1987, p. 142; A. Matilla Tascón, Índice de testamentos y documentos afines. Madrid, 1987, pp. 17-18; J. M. Barbeito, El Alcázar de Madrid, Madrid, 1992; W. Jordan y P. Cherry, El bodegón español de Velázquez a Goya. Londres, 1995, p. 137; P. Cherry, «New documents on Bartolomé Pérez», Apollo March, 1995, p. 43; Pérez Sanchez, Catálogo de la exposición Juan de Avellano, Madrid, 1997.
} 